Review

\title{
Review of Unmanned Aerial Vehicle Swarm Communication Architectures and Routing Protocols
}

\author{
Xi Chen, Jun Tang * and Songyang Lao \\ College of Systems Engineering, National University of Defense Technology, Changsha 410073, China; \\ xichen_0214@163.com (X.C.); laosongyang@nudt.edu.cn (S.L.) \\ * Correspondence: tangjun06@nudt.edu.cn; Tel.: +86-1508-487-7760
}

Received: 15 April 2020; Accepted: 22 May 2020; Published: 25 May 2020

\begin{abstract}
Over the past decades, Unmanned Air Vehicles (UAVs) have achieved outstanding performance in military, commercial and civilian applications. UAVs are increasingly appearing in the form of swarms or formations to meet higher mission requirements. Communication plays an important role in UAV swarm control and coordination. The communication architecture defines how information is exchanged between UAVs or between UAVs and the central control center. Routing protocols help provide reliable end-to-end data transmission. Therefore, it is particularly important to design UAV swarm communication architectures and routing protocols with high performance and stability. This review article details four communication architectures including the advantages and disadvantages. Applicable scenarios are also discussed. In addition, a systematic overview and feasibility research of routing protocols are presented in this paper. To spur further research, the open research issues of UAV swarm communication architectures and routing protocols are also investigated.
\end{abstract}

Keywords: Ad hoc Network; communication architecture; routing protocol; systematic review; UAV Swarm; Unmanned Aerial Vehicle

\section{Introduction}

When first developed, Unmanned Aerial Vehicles (UAVs) were utilized for military applications, and their applications primarily comprised search and destroy missions [1], border monitoring [2] and close air support (CAS) [3]. In addition to military applications, UAVs also play an important role in commerce and public service applications, such as disaster relief [4], forest fire management $[5,6]$, wind assessment [7], civil safety and security [8], agricultural remote sensing [9], traffic monitoring and management [10], and relay networks [11,12]. For example, Drone technology has been utilized for disaster relief and management in the cases of some globally known disasters such as Katrina, the L'Aquila earthquake, Typhoon Morakot, Tohoku Earthquake, and Haiti earthquake [13].

Owing to their advantage of wide applicability, research and development of UAVs has been growing rapidly over the past few years. More and more UAVs appear in formation or in swarm. In 2015, the United States initiated a few UAV swarm research projects, such as the "elves" project, which is part of the Defense Advanced Research Projects Agency and the Low-cost UAV Swarm Technology Project. In 2016, Jungle Wolf UAVs were exhibited at the Farnborough Air Show. China Electronics Technology Group Corporation announced its swarm technology in 2017 when it deployed more than a hundred UAVs [14]. Compared with the single-UAV system, the swarm or formation formed by multi-UAVs has obvious advantages. Table 1 summarizes performance comparisons of single and multi-UAV systems. A detailed explanation of the different criterion is as follows: 
- Survivability: In a single-UAV system, it is considered a failure if a single-UAV is shot down during the mission. However, for multi-UAV systems, a single out of control UAV is nothing serious because other UAVs will continue to operate.

- Scalability: Using large UAVs for single-UAV systems only increases coverage to a certain point. By contrast, multi-UAV systems can easily increase the range of operations [15].

- Speed of mission: Research shows that missions can be completed faster when multi-UAV systems are used [16]. This is especially true for search tasks, as multi-UAV systems can process tasks in parallel, thereby speeding up the time it takes to complete tasks [17].

- Autonomy: For single-UAV systems, the typical mode of operation is that the pilot on the ground has direct real-time control of all aircraft systems. For most multi-UAV systems, the onboard automation ensures controlled flight in accordance with flight plans and other directives received from infrastructures [18].

- Cost: Research shows that missions can be completed at lower costs when multi-UAV systems are used.

- Communication needs: Single-UAV systems need to maintain communication with the ground pilots or infrastructures at all times. By contrast, a multi-UAV system has only one specific UAV that communicates with the ground and forwards the message to other UAVs.

- Radar cross-section: For military applications, multi-UAV systems produce only a small radar cross-section, which enhances the security of military operations [19].

Table 1. Key performance comparisons of a single-Unmanned Aerial Vehicles (UAV) system and multi-UAV system.

\begin{tabular}{ccc}
\hline Features & Single-UAV System & Multi-UAV System \\
\hline Survivability & Poor & High \\
Scalability & Limited & High \\
Speed of mission & Slow & Fast \\
Autonomy & Low & High \\
Cost & High & Low \\
Communication needs & High & Low \\
Radar cross-sections & Large & Small \\
\hline
\end{tabular}

Actually, a swarm of UAVs is a set of aerial robots that work together for a specific goal. The flight of the UAVs is controlled either manually, i.e., by remote control operations, or autonomously by using processors deployed on the drones [20]. Both operations require communication for support. In addition, a high-performance and reliable communication plays an important role in meeting the challenges of a UAV swarm, including coordination and collaboration strategies [21-23], control mechanisms [24-26], security [27-29], mission planning algorithms [30-32], and more.

The communications in UAV swarm include not only UAV-to-UAV(U-T-U) communication but also UAV-to-Infrastructure(U-T-I) communication [33,34].

- U-T-U communication: all UAVs in the swarm establish efficient communication which allows the information to be obtained and exchanged through sensors or radar. Two UAVs can either communicate with each other directly, or indirectly by construct multi-hop communication paths with other UAVs.

- U-T-I communication: UAVs communicate with the fixed central control center, such as a ground station, to obtain real-time mission information. U-T-I communication is usually a direct communication. In the rest of this article, we use infrastructure to represent the central control center.

The U-T-U communication and the U-T-I communication are combined through a communication architecture. In other words, the UAV swarm communication architecture defines how information 
exchanged between the UAVs or between the UAVs and the infrastructure. Further considering the U-T-U communication, the routing protocol plays an important role in achieving reliable end-to-end data transmission [35]. These are also why the swarm communication architecture and routing protocol become important research topics in the field of UAV swarm.

In this article, we focus on UAV swarm communication architectures and routing protocols from both academic and engineering perspectives. We compare the advantages and disadvantages of different architectures and routing protocols, and discuss suitable application scenarios on this basis. We hope that the comparative analysis in our literature review can be useful for deploying effective communication architectures and reliable routing protocols for UAV swarms. The rest of this article is organized as follows: systematic introduction and impersonal comparison of UAV swarm communication architectures are presented in Section 2. Section 3 gives an extensive overview of existing routing protocols, according to an easily accepted classification system. Finally, the article is concluded in Section 4.

\section{Communication Architectures}

Communication architecture plays an important role in the intelligent control and autonomous collaboration of UAV swarms. In the primary stage of the development of a UAV swarm, a central station is available and powerful enough to communicate with the whole UAV swarm. Therefore, the centralized approach was extended from the traditional single-UAV system to UAV swarm communication architecture. As the swarm grows in size, the decentralized approach is proposed. The decentralized approach has a more complex structure and organization, but it does reduce the swarm's dependence on central stations [36]. Many experts and scholars have devoted themselves to the research of UAV swarm communication architectures. In this section, we review these researches and systematically introduce common communication architectures available for UAV swarm systems. Additionally, we also analyze the pros and cons of these architectures.

\subsection{Centralized Communication Architecture}

Centralized communication architecture evolved from single-UAV systems, and was implemented for UAV swarm technology. As shown in Figure 1, there is a central node (i.e., fixed networking infrastructure) to which all UAVs in the swarm are connected. Each UAV forms a one-to-one relationship with the infrastructure and directly receives control commands from the infrastructure. This type of centralized communication architecture is relatively stable, adopts simpler routing algorithms, and has a smaller scale. When the size of the UAV swarm and the coverage area of the mission are small and the mission relatively simple, this type of architecture is more suitable. One of the applications of centralized communication architecture is "UAV-GCS Centralized Data-Oriented Communication Architecture", which is designed for crowd surveillance [37].

However, the connection between UAVs requires infrastructure for transmission. The U-T-I distance is much greater than the U-T-U distance, which causes longer delays. In addition, considering the high mobility of UAVs and the coverage requirements of swarm applications, this architecture is obviously not stable. The infrastructure as a central node also causes the entire communication network to be paralyzed once the ground station or satellite breaks down or is attacked. Therefore, centralized communication architecture has the disadvantage of Single Point of Failure (SPOF). As a result, centralized communication architecture can be regarded as unreliable. 


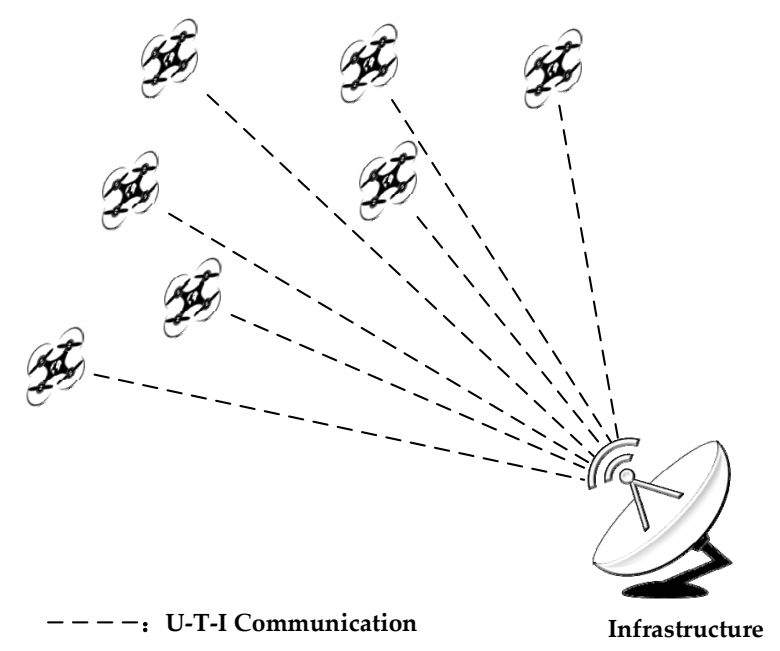

Figure 1. Schematic depicting the centralized communication architecture.

\subsection{Decentralized Communication Architecture}

Because UVAs operate at high speeds and missions may cover large areas, UAVs frequently connect and disconnect to the network. As a result, UAV swarm ad hoc networks are considered the best choice. Under decentralized communication architecture, UAVs conduct real-time interactive communication in an ad hoc manner, thereby eliminating dependence on the infrastructure and eliminating the communication range restrictions [38].

\subsubsection{Single-Group Swarm Ad hoc Network}

In a "single-group swarm Ad hoc network" (Figure 2), an internal communication of the swarm does not depend on the infrastructure. The communication between the swarm and the infrastructure is a single point link relying on a specific UAV called gateway UAV. In this system, other UAVs are relay nodes that forward data within the swarm. Using this method, UAVs in the swarm can share situation information in real time to optimize collaborative control and improve efficiency. Similarly, mutual communication between the gateway UAV and infrastructure also enables the upload and download of swarm information, including instructional information. With regard to the gateway $\mathrm{UAV}$, two additional types of transceivers are necessary: one for communicating with other UAVs at low power and short distances and the other for communication with infrastructure at high power and long reach. As a result, other UAVs in the swarm only need to carry low-cost and lightweight short-reach transceivers. This not only greatly extends the communication range of the network to allow for large coverage requirements, but also makes small UAVs with smaller payloads more useful [39]. However, in order to guarantee the consistent connectivity of the swarm, "single-group swarm Ad hoc network" architecture requires that the flight patterns (speed and heading orientations) of all UAVs in the swarm must be alike. Therefore, a group of small size UAVs is appropriate for scenarios that utilize communication architecture. One example of a "single-group swarm Ad hoc network" is the UAV cloudlet layer in Disaster Resilient three-layered architecture for Public Safety Long-Term Evolution (DR-PSLTE) [40].

For mission requirements, intra-swarm communication architecture has undergone several changes [33]. Figure 3a-c shows three common intra-swarm communication architectures.

Figure 3a depicts an example of ring architecture. UAVs in ring architecture form a closed communication loop through a bidirectional connection. Any UAV can act as the gateway node for the swarm. When a direct link between two adjacent UAVs fails, the target UAV can link back through the communication loop. Therefore, the ring architecture has a certain stability. However, it is clear that this architecture lacks scalability. As shown in Figure $3 \mathrm{~b}$, communication is organized in the form of star architecture. The gateway UAV is in the middle, and not only communicates with the 
infrastructure but also with the entire UAV swarm. It is not difficult to see from Figure $3 \mathrm{~b}$ that star architecture has the inherent disadvantage of a SPOF. That is, if the gateway node fails, it will cause the entire system to fail.

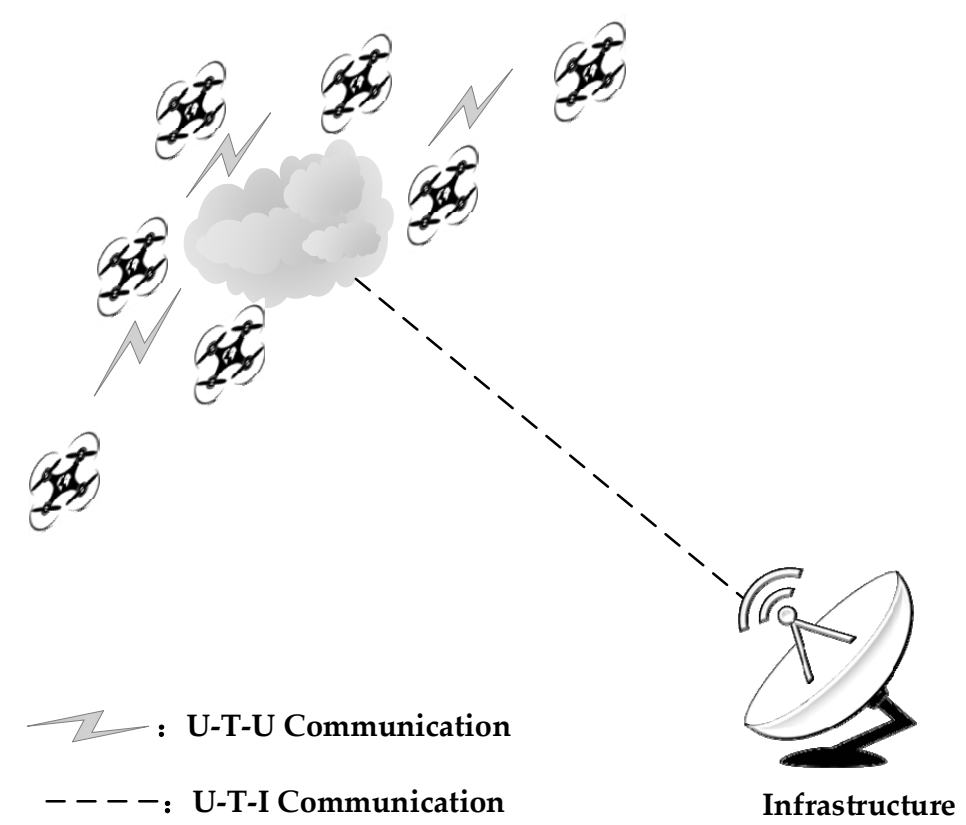

Figure 2. Schematic showing a single-group swarm Ad hoc network.

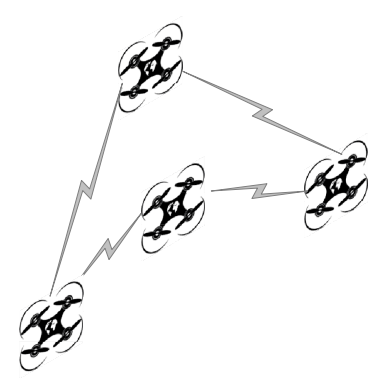

(a)

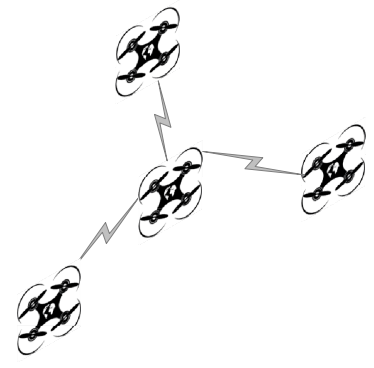

(b)

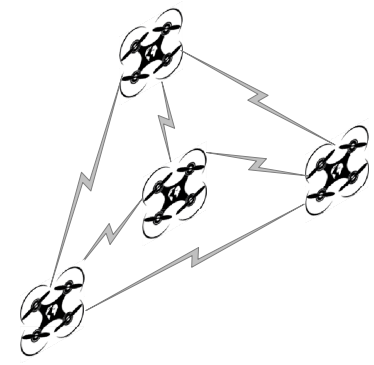

(c)

Figure 3. Intra-swarm communication architecture: (a) ring architecture, (b) star architecture, (c) meshed architecture.

Meshed architecture is a combination of ring and star architectures and has the advantages of both systems (Figure 3c). All the UAV nodes in the swarm have the same capabilities, with both terminal nodes and routing functions. The information stream from one node to another can be implemented in different forms, and any UAV can act as a gateway node for the swarm. Meshed architecture has now become the standard for intra-swarm communication systems.

However, the diversification of missions results in higher demands on the composition of the UAV in a swarm. Practical applications often require the swarm to utilize not only small UAVs, but also medium and large UAVs. Therefore, the aforementioned "single-group swarm Ad hoc network" architecture obviously does not meet these needs. While similar UAVs can often fly close in proximity, different types of UAVs can be far away from each other. Therefore, the UAVs in the swarm are divided into different groups, with similar UAVs located within the same proximity. These are known as "multi-group swarm Ad hoc network" and "multi-layer swarm Ad hoc network" architectures, as described below. 


\subsubsection{Multi-Group Swarm Ad hoc Network}

To address the shortcomings of a "single-group swarm Ad hoc network", the "multi-group swarm Ad hoc network" (Figure 4) integrates both a centralized architecture and a "single-group swarm Ad hoc network" architecture. Different types of groups have different applications depending on the mission. Overall, the architecture is organized in a centralized manner as described in Section 2.1. While the difference is that the intra-group UAVs communicate with each other in an Ad hoc manner. The intra-group communication architectures are the same as the intra-swarm communication architectures described in Section 2.2.1. Inter-group communications, i.e., the Group-to-Group (G-T-G) communications, are performed through the infrastructure, so the gateway UAVs are still responsible for communicating with the infrastructure. When mission scenarios require a variety of UAVs, a "multi-group swarm Ad hoc network" architecture can be employed. However, attention must be paid to the robustness of this architecture, as the "multi-group swarm Ad hoc network" architecture is semi-centralized. At the same time, for G-T-G communication between two UAVs in different groups, "multi-group swarm Ad hoc network" architecture still suffers from high latency. One specific application of multi-group architecture is multi-theater joint operations for military operations. The central control center communicates with different UAV swarms, and the swarms rush to the mission area from various directions, according to the control instructions [41].

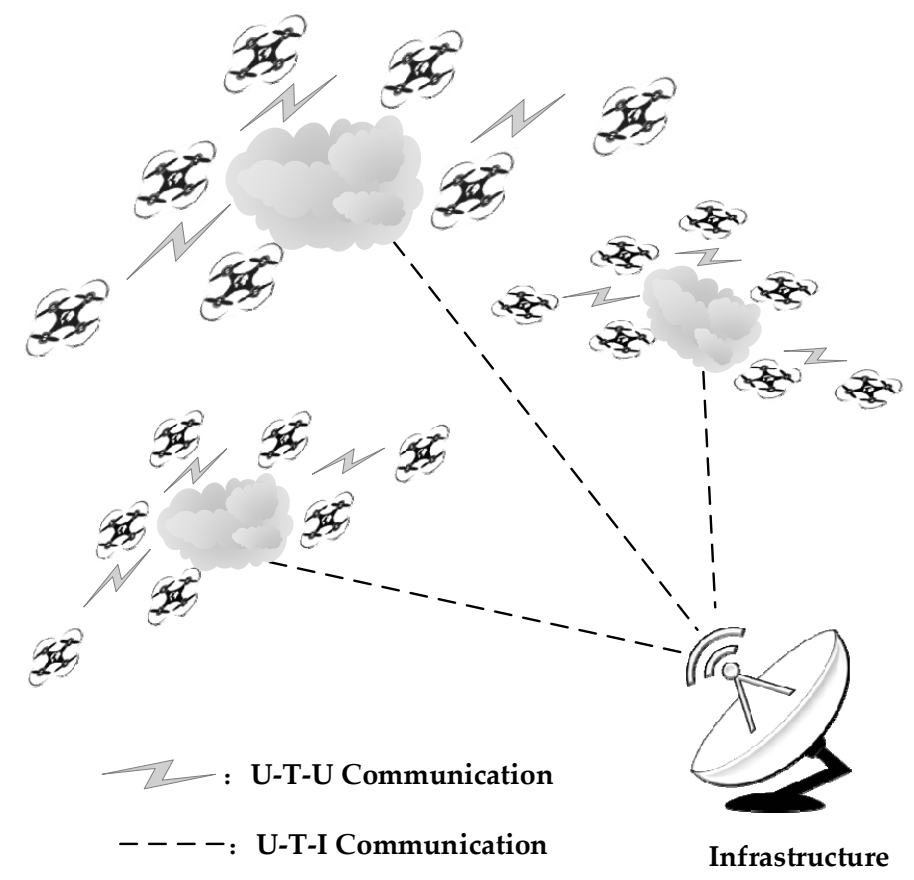

Figure 4. Schematic of a multi-group swarm Ad hoc network.

\subsubsection{Multi-layer Swarm Ad hoc Network}

"Multi-layer swarm Ad hoc network" architecture is another type of architecture that is suitable for a mass variety of UAVs. As shown in Figure 5, this architecture is significantly advanced compared to the "multi-group swarm Ad hoc network" architecture. A group of adjacent UAVs of the same type constitutes an Ad hoc network, which is the first layer of the communication architecture. The architecture of intra-group communications is elaborated as explained in Section 2.2.1. Different types of UAV groups rely on gateway UAVs to perform G-T-G communication, which comprises the second layer. The closest gateway UAV communicates with the infrastructure, which is the third layer of the architecture. Communication between any two UAVs in the "multi-layer swarm Ad hoc network" architecture does not require infrastructure relay. Mutual communication of UAVs in the same group takes place at the first level. Communication between UAVs in different groups is routed 
through the gateway UAV. Data packets go through the first and second layers in turn. Therefore, there is no SPOF in the "multi-layer swarm Ad hoc network," and this type of architecture is robust.

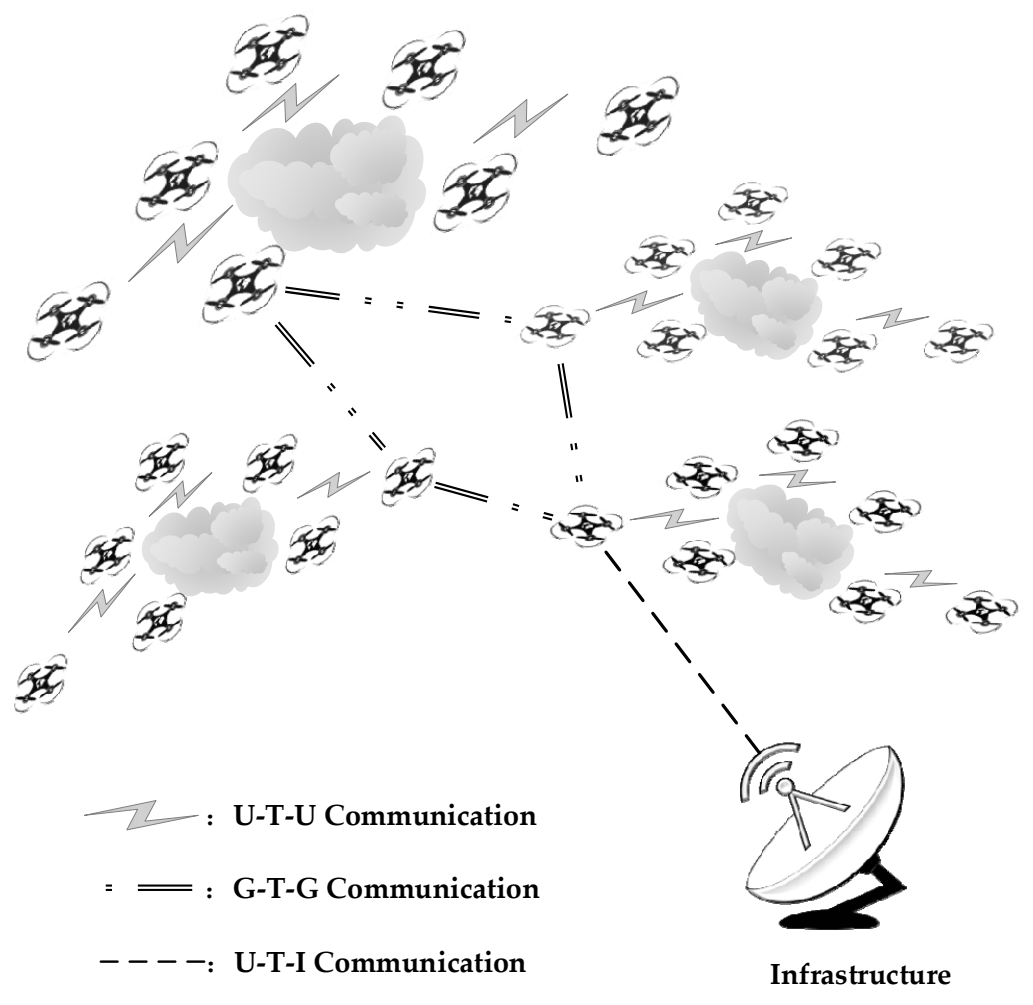

Figure 5. Schematic of multi-layer swarm Ad hoc network.

In a mission, when the number of UAVs changes, the "multi-layer swarm Ad hoc network architecture compensate for the increase or decrease of UAV nodes and quickly implement network reconstruction. Therefore, the multi-layer swarm Ad hoc network architecture is appropriate for scenarios where UAV swarm missions are complicated: there are a huge number of UAVs executing the mission, the network topology changes, and communication between the UAV nodes is frequent. With the research and development of UAV swarms and the advancement of communication technology, one possible improvement includes the number of layers required to form a swarm Ad hoc network architecture with more UAVs, resulting in larger task coverage and a more robust network [35].

\subsection{Remarks}

As discussed, we know that UAV swarm communication architecture technology has already made great progress. When faced with different mission scenarios, there are different communication architectures to choose from. Table 2 summarizes the advantages and disadvantages of the four mentioned architectures. Centralized communication architecture is suitable for scenarios where the UAV swarm is small, and the task is relatively simple. Each individual UAV requires a long-range communication link with the infrastructure. The decentralized communication architecture expands communication coverage through a multi-hop network. The dedicated gateway UAV is responsible for U-T-I communication. The "single-group swarm Ad hoc network" architecture is appropriate for a swarm of the same type UAVs, while "multi-group swarm Ad hoc network" and "multi-layer swarm Ad hoc network" architectures can be deployed using different types of UAVs. In a "multi-group swarm Ad hoc network", communication between two different groups can also suffer from delays. In addition, in terms of robustness, "multi-layer swarm Ad hoc network" architecture is a relatively reliable system because it overcomes SPOF. 
Table 2. Summary of Communication Architectures.

\begin{tabular}{ccccc}
\hline \multirow{2}{*}{ Features } & $\begin{array}{c}\text { Centralized Communication } \\
\text { Architecture }\end{array}$ & \multicolumn{2}{c}{ Decentralized Communication Architecture } \\
\cline { 3 - 5 } & & Single-Group & Multi-Group & Multi-Layer \\
\hline Multi-hop Communication & $\times$ & $\sqrt{ }$ & $\sqrt{ }$ & $\sqrt{ }$ \\
UAVs Relay Traffic & $\times$ & $\sqrt{ }$ & $\sqrt{ }$ \\
Different Types of UAVs & $\times$ & $\times$ & $\sqrt{ }$ & $\sqrt{ }$ \\
Self-configuration & $\times$ & $\sqrt{ }$ & $\times$ \\
Limited Coverage & $\sqrt{ }$ & $\times$ & $\sqrt{ }$ & $\times$ \\
Single Point of Failure & $\sqrt{ }$ & $\times$ & $\times$ & $\sqrt{ }$ \\
Robustness & $\sqrt{ }$ & & & \\
\hline
\end{tabular}

Note: " $\sqrt{ }$ " = supported, " $\times$ " = not supported.

When discussing the advantages and disadvantages of the UAV swarm communication architectures, we often focus on the requirements of high coverage and maintaining connectivity. High coverage plays an important role in gathering intelligence and analyzing situations. Only by maintaining connectivity can the real-time communication of the swarm be guaranteed. However, UAV swarms often perform tasks in unknown environments, and the appearance of threats and obstacles is random in time and space. Therefore, it is essential that members withdraw or rejoin. This leads to the impossibility for a disruption-free connectivity. This mainly depends on signal attenuation due to propagation loss. To achieve an uninterrupted connection, on the one hand, the distance in the UAV swarm ad hoc network configuration should not exceed the sensitivity of the receiver, and must be limited to the minimum signal-to-noise ratio (SNR) or receive signal strength indicators (RSSI) range, respectively Inside [42]. On the other hand, the wisdom of bird flocks and fish schools in nature is worth learning from. UAVs in a swarm should be able to react cognitively to changes of the environment to adapt their movement to positions with channel characteristics. This is undoubtedly beneficial for achieving uninterrupted connections. In addition, existing researchers have used the high-efficiency bandwidth of $4 \mathrm{G}$ wireless networks to improve the connection stability of UAV swarm in wide coverage areas [43]. The emerging 5G wireless network will provide higher technical support for these studies.

\section{Routing Protocols}

In the last section, we present four current UAV swarm communication architectures, and find that the multi-layer swarm Ad hoc network architecture has better comprehensive performance through comparison. Considering the U-T-U communication, routing protocol plays a crucial role in reliable end-to-end data transmission. This makes routing protocol an attractive research topic in the field of UAV swarm communication. However, due to the rapid mobility of UAVs, the instability of air links, the limited resources, and the variability of Quality of Service (QoS) requirements, routing in UAV swarm communication network has become a vital task [44,45]. Moreover, the traditional Ad hoc routing protocols cannot be used in UAV swarm communication without improvement [46,47]. Therefore, designing routing protocols that fit most mission scenarios and UAV characteristics remains a challenge for researchers.

In this section, we first introduce the common UAV swarm communication routing technology, which is the basis of the routing protocol design and implementation. Then, we give the routing protocol a classification. The classification is based on the technologies followed by the routing protocols. Further, we provide a detailed overview of each class of routing protocols. At the end of this section, we remark the advantages and disadvantages of routing protocols.

\subsection{Routing Technologies}

Routing technologies provides support for the implementation of routing protocols. The implementation of a routing protocol is usually an improvement on the basic routing technologies or a combination of several routing technologies. UAV swarm Ad hoc network is developed from 
the traditional Ad hoc network. Therefore, the conventional routing technologies can also be used in the UAV swarm Ad hoc network after analysis, improvement and combination. Figure 6 shows the six common routing technologies of the UAV ad hoc network: store-carry-forward, greedy forward, path discover, single-path, multi-path and predictive routing.

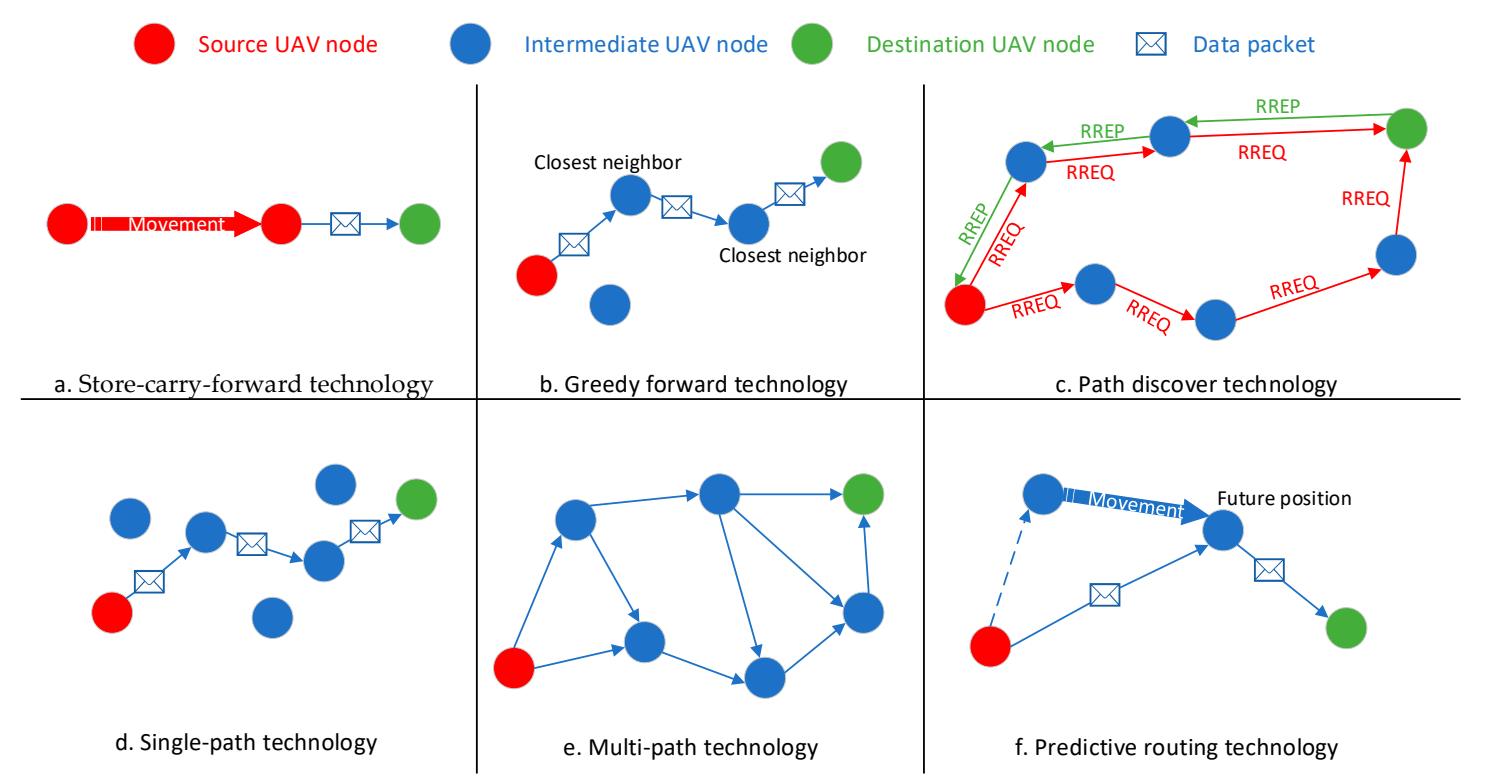

Figure 6. The rationales for common routing technologies of UAV ad hoc network. (a) Store-carryforward technology, (b) Greedy forward technology, (c) Path discover technology, (d) Single-path technology, (e) Multi-path technology, (f) Predictive routing technology.

(1) Store-carry-forward technology: when no relay node can be found at a certain time, the current node will store and carry the datagram until it finds the forwarding node. This technology is suitable for intermittent network, but the disadvantage is that it produces a large delay.

(2) Greedy forward technology: forwarding principle is to select the neighbor node closest to the destination as the relay node until the datagram is sent to the destination. It can be used in scenarios where the deployment of UAVs is intensive. However, when a node is closest to the destination and there is no path to neighbor node, it will cause a failure. In this case, it should be combined with other technologies to increase the reliability of the technology.

(3) Path discover technology: the core is through the flooding of routing request (RREQ), maximizing the accessibility of the path. This technique reduces the likelihood of communication interruptions when the current node loses the destinated geographic location. But the disadvantage is that it consumes bandwidth resources excessively.

(4) Single-path technology: characterized by the use of a single path for data transmission. Suitable for extremely limited bandwidth resources. However, it has the disadvantage of poor robustness. There is no alternative path for network failure, so it is easy to lose packets. This technique is rarely used in UAV swarm communication scenarios.

(5) Multi-path technology: Multi-path propagation technology can effectively improve the robustness of the link. When one link fails, other links can take over. It is suitable for scenarios where high link reliability is required. The disadvantage is that when the multi-path intersections fail, the network will have a loop which will block the network.

(6) Predictive routing technology: The predictive routing technology predicts the future position of a node by its current position, velocity and direction, and further chooses the next optimal hop node. This technology is applicable to scenarios where the positions of nodes change rapidly, so it is widely used in a UAV swarm Ad hoc network. 


\subsection{The Classification of Routing Protocols}

At the beginning of the research and experiment of UAV swarm communication, researchers studied and optimized the routing protocols of traditional Ad hoc networks. However, as the study progressed, the researchers found that most of the traditional routing protocols were not suitable for UAV swarm communication. On the one hand, UAV nodes have properties different from traditional nodes, such as the rapid mobility. On the other hand, different task scenarios have different requirements for routing protocols. Therefore, to get a routing protocol for a swarm of UAVs in Ad hoc networks, the researchers improved some traditional routing protocols. At the same time, a number of new, dedicated routing protocols for UAV swarm have been proposed. As shown in Figure 7, the protocols can be divided into three large categories and many subclasses.

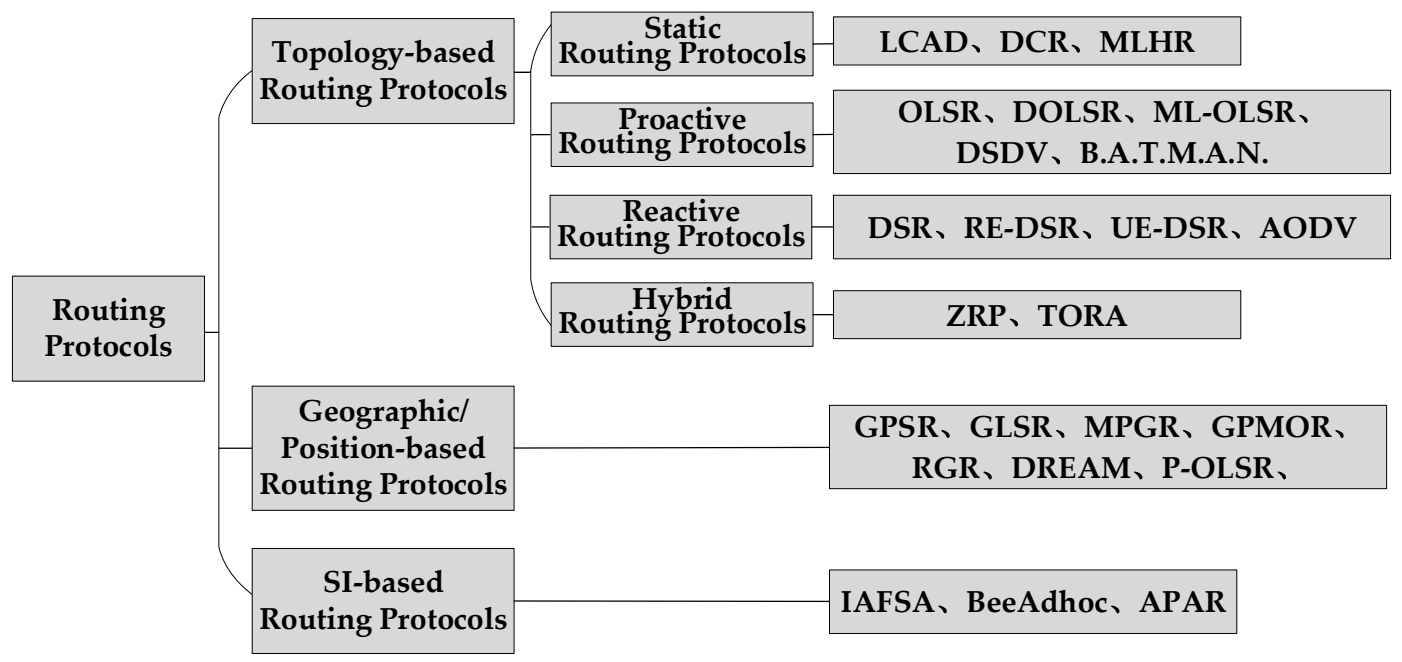

Figure 7. Classification of all routing protocols summarized in this article.

In the following sections, we detail these routing protocols according to the categories shown in Figure 7. For the highlights, we also clearly state the original works and the subsequent follow-up studies. A discussion of the advantages and disadvantages of various routing protocols and usage scenarios follows.

\subsection{Topology-Based Routing Protocols}

Topology-based routing protocols use Internet Protocol (IP) addresses to define the nodes and use existing link information to forward packets through appropriate paths. Topology-based routing protocols can be divided into static routing protocols, proactive routing protocols, reactive routing protocols and hybrid routing protocols.

\subsubsection{Static Routing Protocols}

Static routing protocols have static and non-updatable routing tables. They are mostly used in situations with a fixed topology and no task updates. Due to the lack of fault tolerance and adaptability to dynamic environments, traditional static routing protocols have limited applications for UAV swarm systems. The following are three static routing protocols:

(1) Load Carry and Deliver Routing (LCAD) protocol is proposed by Le et al. in [48] and is an earlier routing protocol used by the centralized communication architecture. The infrastructure passes data packets to a UAV, which then carries and delivers the data packets to its destination [49]. The goal of LCAD is to maximize network throughput while increasing security. It minimizes the number of hops to achieve batch data transmission and delay tolerance requirements. Moreover, the disadvantage of LCAD is that as the communication distance between the UAVs increases, the delay increases significantly. 
(2) Data Centric Routing (DCR): for practical applications, a one-to-many data transmission requirement exists in multi-UAV systems. DCR works well with a "single-group swarm Ad hoc network", in which the gateway UAV is responsible for distributing information to other nodes [50-52]. A typical application is the "publish-subscribe" model, which can realize automatic connections between data publishers and subscribers, as well as collect traffic $[53,54]$. Due to the minimal assistance required between UAVs, DCR is preferred when the system has a limited number of UAVs and a planned flight path.

(3) Multilevel Hierarchical Routing (MLHR) is migrated from the mobile vehicle network, which solves the scalability problem of large-scale vehicle networks [30]. As described in the "multi-layer swarm ad hoc network", UAV swarms can be divided into groups based on the size and function of the UAVs. Communication networks are therefore organized as a hierarchical structure. Only gateway UAVs are responsible for G-T-G communication. The gateway UAV sends data to other UAV nodes in the group using a broadcast $[17,39]$. Figure 8 depicts this pictorially. The current literature [55] has proposed the use of a clustering algorithm to select gateway UAVs based on geographical information. This routing model effectively solves the scalability problem and significantly improves the stability of the dynamic network.

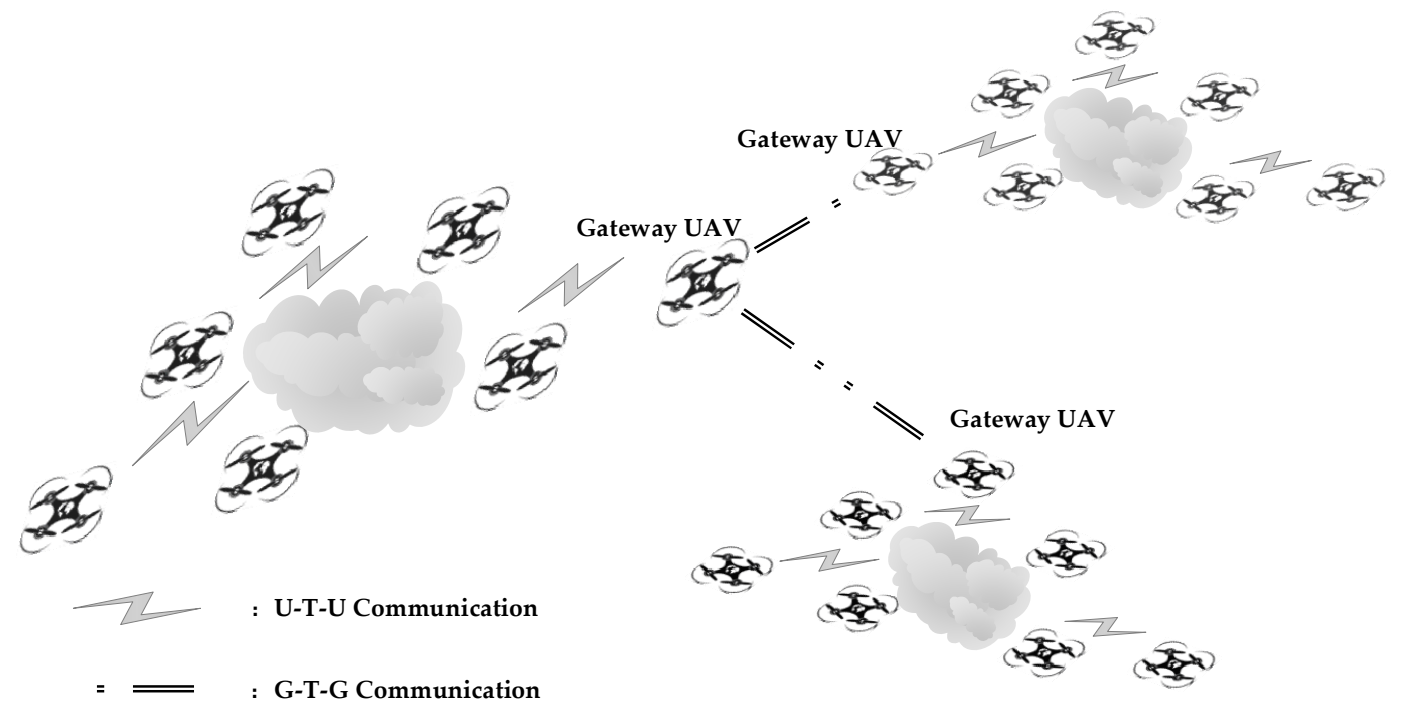

Figure 8. Multilevel Hierarchical Routing in a UAV swarm Ad hoc network.

\subsubsection{Proactive Routing Protocols}

A proactive routing protocol (PRP) can update the routing table periodically to keep it up to date. The advantages are that it can accurately reflect the topology of the network, and the delay in obtaining routes is minimal. Therefore, PRP is suitable for applications with real-time requirements. However, to update the routing tables periodically, a number of messages exchange continuously between nodes. That is why PRPs are not suitable for UAV swarm network whose nodes move fast. When network scale and mobility increase to a certain degree, most PRP schemes are not applicable. At present, the most popular proactive routing protocols are the Optimized Link State Routing (OLSR) protocol, Destination Sequenced Distance Vector (DSDV) protocol and their variations.

(1) Optimized Link State Routing (OLSR) protocol is a link-state optimized routing protocol originally for flat topology [56]. By flooding the link-state of neighbors to other nodes, the topology information is exchanged between nodes. Nodes use the shortest path algorithm to destinations to choose the next hop. K Singh et al. [57] applied the OLSR routing in flying ad hoc networks and then analyzed the applicability of OLSR for a flying ad hoc network [58]. Some other researchers also compared the OLSR with other routing protocols [58,59]. In a UAV Ad hoc network, the location of nodes and the state of links change rapidly. This would cause not only packed loss but would also put 
a strain on already constrained bandwidth [38]. Optimizations involve abandoning the traditional approach of non-selectively forwarding topology control (TC) packets and instead adopting the method of selecting neighbors as multiple point relays (MPR). Through this mechanism, OLSR reduces the protocol overhead. The MPR technology, TC strategy, and routing optimization technology have become the main means for designing efficient OLSR protocols. Therefore, in recent years, the OLSR protocols and the MPR optimization algorithm have been extensively studied, becoming of the most commonly used routing algorithms for ad hoc networks.

Although the overhead caused by the periodic flooding strategy is reduced by MPR, problems such as recalculation of routes and selection of MPR still plague researchers. Therefore, many variants have been designed and proposed. A.I. et al. in [60] proposed a cross layer design for UAV communication networks and further proposed a Directional OLSR (DOLSR) protocol based on directional antennas for UAV ad hoc networks [61]. The DOLSR minimizes latency by reducing the number of MPR members. Zheng et al. [62] proposed a Mobility and Load-aware OLSR (ML-OLSR) protocol, which added mobility and load-aware algorithms to the OLSR protocol. This protocol successfully obtained a good delivery rate and latency performance.

(2) DSDV $[17,63,64]$ : In the DSDV protocol, the network has nodes for every path from source to destination, before demand has emerged. Each node in the network has a routing table that lists all valid destination nodes and the number of nodes that can reach the destination node. Each entry in the routing table of the destination node is marked with a node serial number. For the information in the routing table to be consistent with regards to the dynamically changing topology, it must be updated frequently. DSDV routing table updates are classified into "full-dump" and "incremental-dump". "Full-dump" sends the entire routing table to its neighbors, which requires multiple packets; "incremental-dump" only sends the modified portions of routing information to its neighbors, and therefore only one packet is needed. When the network is relatively stable, "incremental-dump" can avoid extra traffic and reduces the burden on the network. However, in a network with rapidly changing topology such as a UAV swarm network, the update process increases network bandwidth sharply and also puts the DSDV protocol at a disadvantage. In [65], the authors analyzed the adaptability of the DSDV protocol for UAV ad hoc networks and compared the performance with other protocols.

In addition to OLSR and DSDV, there are also some relatively new proactive routing protocols. The Better Approach to Mobile Ad hoc Networking (B.A.T.M.A.N.) method proactively maintains the information of all nodes and identifies the best next hop for each destination [66]. D.S. Sandhu et al. [67] have reviewed the comparative studies of B.A.T.M.A.N. The results in $[68,69]$ show that the B.A.T.M.A.N. method and OLSR behaves similarly for small network sizes and bandwidth-limited networks. But in scenarios of large number of nodes, B.A.T.M.A.N. outperforms OLSR. This may become a new method for routing protocols of the UAV swarm ad hoc network.

\subsubsection{Reactive Routing Protocols}

The reactive routing protocol (RRP) is also called on-demand routing protocol because it starts the route discovery procedure only when a message needs to be sent. Therefore, the required routing information cache is small [70]. When the network is not overburdened, the control overhead of RRPs is much smaller than the PRPs. However, because the source node needs to perform route discovery before data transmission, RRPs suffer from high transmission delays. Typical RRPs include Dynamic Source Routing (DSR), Ad hoc On-Demand Distance Vector (AODV), and more.

(1) Dynamic Source Routing (DSR) protocol is a widely used and standardized RRP method for ad hoc networks. The most obvious advantage of the DSR protocol is that it does not have specific network infrastructure requirements. This protocol allows the network to self-organize and self-configure. Each data packet in a DSR protocol contains a complete list of routing nodes, so all nodes that forward or listen to this packet will store the routing information as a backup. Therefore, no matter how the nodes move and the network topology changes, they can maintain performance. There are many follow-up studies on DSR's adaptability in UAV Ad hoc networks. In [71], authors developed a UAV 
ad hoc network test platform based on the DSR protocol. Khare et al. [72] found that due to the high mobility and topology instability of UAV nodes, DSR is more suitable for UAV ad hoc networks than proactive protocols. Li et al. [73] proposed the Restrict DSR (RE-DSR) for limiting the maximum hop count of Route Requests (RREQ), which can save routing storage space and reduce routing overhead for UAV nodes. Then they proposed UAV Energy DSR (UE-DSR) for ad hoc networks consisting of small UAVs for reconnaissance missions [74].

(2) Ad hoc On-Demand Distance Vector (AODV) [75] protocol is an RRP method based on DSDV and DSR. There is no maintenance of global routing information for the entire network, but only the destination addresses in data packets. Therefore, the overhead is low. Before the node sends data, it first looks up the routing table. If there is one path to the destination node, the data packet is sent to the next hop according to the routing table. However, if there is no available path, the source node broadcasts Route Request (RREQ) to neighboring nodes. After receiving the non-repeating RREQ, the neighboring nodes establish or update revers routes. Then they continue to broadcast the RREQ until the destination node receives. If the current node contains a valid route to the destination node, the route discovery process can also terminate itself. Then, a Route Reply (RREP) is returned to the source node along the reverse path. When the RREP returns, a forward route entry is established, and when the source node receives the RREP, it establishes a route from the source to the destination node. In recent years, there have been many studies on applying AODV to UAV communication networks, and some have also proposed variations of AODV. Biomo et al. [76] aimed at minimizing the number of hops in the route discovery process, and further proposed a route reliability criterion in which path update degree, path length, and path reliability are used as path selection criteria.

\subsubsection{Hybrid Routing Protocols}

To overcome the huge overhead of control messages in PRP and the large delay of the route discovery process in RRP, Hybrid Routing Protocols (HRP) were introduced. HRP divides large-scale Ad hoc networks into zones. PRP is used between adjacent nodes in the same zone, while RRP is used between nodes in different zones. Adjusting the routing strategy according to network characteristics can not only reduce the routing overhead but also decrease the large delay in route discovery. However, the highly dynamic nature of UAV ad hoc networks makes it difficult for HRP to obtain and maintain information. The most representative HRPs are Zone Routing Protocol (ZRP) and Temporarily Ordered Routing Algorithm (TORA), as described below.

(1) Zone Routing Protocol (ZRP) [77,78] is a routing protocol that makes full use of routing zone topology. The application range of PRP is limited to a zone measured by the number of hops. Accordingly, the number and propagation of routing control packets is reduced. When communicating with nodes outside the zone, the RRP is selected. Compared with the simple PRP, ZRP can greatly reduce routing overhead. When compared with RRP, its time route convergence and transmission delays are relatively small. In the case of a large network load, the performance of ZRP does not decrease much, which makes it a routing protocol with great development potential. At present, the zone radius in ZRP is generally specified in advance, which limits the adaptability of the protocol. Therefore, improving ZRP with adaptive zone radii has been a research hotspot. Liu et al. [56] proposed a novel clustering algorithm for UAV networks. First, the UAVs are clustered on the ground. Then each cluster head is selected in the zone based on geographic information and each cluster structure is adjusted according to the mission information. C Zang [79] et al. also focus on the clustering algorithm and they proposed another mobile prediction clustering algorithm. To solve the cluster update problem, the tree structure, the link failure time and the nodes' movement model are used to predict the movement of UAVs and further to update the network topology.

(2) Temporarily Ordered Routing Algorithm (TORA) [80] is a hybrid distributed routing protocol with high adaptability. The distributed algorithm is embodied in the maintenance of the routing information. Each node only updates the routing information of neighboring nodes. In response to the high mobility of UAVs, TORA minimizes the sensitivity to topology changes to limit the spread of 
control messages. It is worth noting that the shortest path algorithm is not the choice of TORA. Instead, it usually uses longer routes to quickly discover new routes in the event of a link outage. In TORA, different "height" values are used to mark the UAV nodes. Based on this, a directed acyclic routing structure is constructed to achieve effective traffic forwarding.

\subsection{Geographic/Position-Based Routing Protocols}

Due to the high mobility of nodes in the UAV ad hoc network, it is hard to maintain the routing table. At the same time, traditional routing protocols will cause significant overhead to find the routing repeatedly before sending packets. In response to these problems, researchers have proposed routing protocols based on geographical position information. In this type of protocol, nodes can use location services, such as reactive location services (RLS) [81], grid location services (GLS) [82], or hierarchical location services (HLS) [59]. Geographic/position-based routing protocol is more suitable for highly dynamic networks, including UAV communication networks.

(1) Greedy Perimeter Stateless Routing (GPSR) is a position-based routing protocol and is originally proposed for mobile ad hoc networks [83]. In a comparative study [84], authors compared the proactive, reactive, and position-based routing protocols in a swarm of UAVs. The results show that the performance of the GPSR protocol is better than others. Shirani et al. examined the position-based routing protocols including GPSR for flying Ad hoc networks [85]. They draw a conclusion that the GPSR protocol is applicable for a densely deployed UAV network. However, the generalizability and reliability of this routing protocol have yet to be improved, thus leading to the emergence of many variants.

Geographic Load Share Routing (GLSR) proposed by Medina et al. [86] is an extension of GPSR. The main contribution is that the GLSR uses "distance of advance" to select the appropriate next hop from multiple paths from the source node to the destination node, thus making the path more reliable. As a result, Medina's team has published a number of articles on the GLSR protocol [87-89].

Based on the same principle as GPSR, Lin et al. [90] proposed Mobility Prediction-based Geographic Routing (MPGR). The innovation of this protocol is the use of Gaussian function-based motion prediction method. The result of motion prediction can be used to evaluate the connectivity of the UAV nodes, and furthermore, to select a reliable next hop. In their other study [91], Geographic Position Mobility Oriented Routing (GPMOR) was proposed. UAV nodes can get their own location information via Global Positioning System (GPS). Each UAV periodically exchanges location information with neighbor nodes. GPMOR also uses the "Gaussian-Markov mobility model" to predict the movement of the UAVs.

(2) Shirani et al. combines the AODV protocol with Greedy Geographic Forwarding (GGF) technology and further proposed Reactive-Greedy-Reactive (RGR) routing protocol [92]. To obtain the destination address, RGR uses the location information of UAVs. AODV's RREQ / RREP structure and GGF technology complement each other. The protocol first finds the initial path and carries out data transmission according to the way of AODV protocol. When the transmission is cut off accidentally, the strategy will be switched to GGF mode. This protocol improves the packet delivery ratio and reduces the latency. However, due to the high mobility of the UAVs, if the geographic position information of the next hop is not updated in a timely manner, a packet loss fault will occur. Nevertheless, RGR has great application potential for tracking, searching, and multitasking of UAV swarms.

There are some other geographic/position-based routing protocol. Distance Routing Effect Algorithm for Mobility (DREAM) [93] uses a location table to store the geographical coordinates of nodes. This consumes lesser bandwidth. But it seems that DREAM is more complex than the traditional flooding strategy [94]. S. Rosati et al. [3] proposed the prediction-OLSR protocol, which uses Global Position System (GPS) information to assist routing decisions. At the same time, the expected transmission count is weighted through the relative speed between the nodes. 


\subsection{Swarm Intelligence-Based Routing Protocols}

Swarm intelligence (SI) is a multi-agent self-organizing system. Inspired by the swarming patterns of fish, birds, insects, etc., we can apply SI to mobile robots. Additionally, the SI brings new ideas for optimizing complex collaborative tasks. In the routing protocol of UAV swarm systems, there are also embodiments of SI. In order to solve the problems of communication range expansion and information leakage, which are caused by the increasing scale of swarm, one study [95] proposed an Improved Artificial Fish-Swarm Algorithm (IAFSA). By adjusting the topology of the group, the proposed wireless communication model achieves secure communication purposes. In addition, there are other routing protocols specifically designed for UAV communications such as the Bee colony algorithm-based Ad hoc network (BeeAdhoc) [96], and Ant colony optimization-based Polymorphism-Aware Routing (APAR) [97].

\subsection{Remarks}

In order to have a deeper understanding of the routing protocols of UAV swarm Ad hoc network, Table 3 compares the protocols summarized in this paper. The static routing protocols are not suitable for dynamic topology networks like UAV swarm Ad hoc network due to the fixed routing tables and less scalability. The proactive routing protocols have large overhead for maintaining tables up-to-date. Moreover, their slow reaction to topology changes results in delays. The main disadvantage of the reactive routing protocols is the high latency in routing finding. Source routing does not scale well, for large network overheads may increase because of large header size. Hybrid routing protocols combine the proactive and reactive protocols to overcome the limitations. However, in UAV networks dynamic nodes and link behaviors make it difficult to obtain and maintain information. Therefore, the topology-based routing protocols are not suitable for scenarios characterized by high dynamic movement and a large number of nodes. The geographic/position-based routing protocols add geographical location attribute to UAV nodes. This makes it outstanding in dealing with high mobility of nodes and frequent change of topology in UAV networks.

Table 3. Summary of Routing Protocols.

\begin{tabular}{|c|c|c|c|c|c|c|c|c|c|c|}
\hline $\begin{array}{c}\text { Routing } \\
\text { Protocols }\end{array}$ & $\begin{array}{c}\text { Suitable for } \\
\text { Dynamic Topology }\end{array}$ & Scalable & $\begin{array}{l}\text { Packet Delivery } \\
\text { Delays }\end{array}$ & $\begin{array}{l}\text { Routing Finding } \\
\text { Delays }\end{array}$ & $\begin{array}{c}\text { Large } \\
\text { Overhead }\end{array}$ & $\begin{array}{c}\text { Routing } \\
\text { Loops }\end{array}$ & $\begin{array}{l}\text { Packet } \\
\text { Loss }\end{array}$ & $\begin{array}{l}\text { Link } \\
\text { Failure }\end{array}$ & $\begin{array}{c}\text { High } \\
\text { Bandwidth }\end{array}$ & $\begin{array}{l}\text { Location } \\
\text { Services }\end{array}$ \\
\hline & & & & Static & & & & & & \\
\hline LCAD & $x$ & $x$ & $\sqrt{ }$ & $x$ & $\sqrt{ }$ & $\sqrt{ }$ & $\sqrt{ }$ & $\sqrt{ }$ & $x$ & $x$ \\
\hline DCR & $x$ & $x$ & $x$ & $x$ & $\sqrt{ }$ & $\sqrt{ }$ & $\sqrt{ }$ & $\sqrt{ }$ & $x$ & $x$ \\
\hline \multirow[t]{2}{*}{ MLHR } & $x$ & $\sqrt{ }$ & $\sqrt{ }$ & $x$ & $\sqrt{ }$ & $\sqrt{ }$ & $\sqrt{ }$ & $\sqrt{ }$ & $x$ & $\sqrt{ }$ \\
\hline & & & & Proactive & & & & & & \\
\hline OLSR & $x$ & $\sqrt{ }$ & $\sqrt{ }$ & $x$ & $x$ & $\sqrt{ }$ & $\sqrt{ }$ & $x$ & $\sqrt{ }$ & $x$ \\
\hline DOLSR & $x$ & $\sqrt{ }$ & $x$ & $x$ & $x$ & $\sqrt{ }$ & $\sqrt{ }$ & $x$ & $\sqrt{ }$ & $x$ \\
\hline ML-OLSR & $x$ & $\sqrt{ }$ & $x$ & $\sqrt{ }$ & $x$ & $\sqrt{ }$ & $\sqrt{ }$ & $x$ & $\sqrt{ }$ & $x$ \\
\hline DSDV & $x$ & $\sqrt{ }$ & $x$ & $x$ & $x$ & $\sqrt{ }$ & $\sqrt{ }$ & $x$ & $\sqrt{ }$ & $x$ \\
\hline \multirow[t]{2}{*}{ B.A.T.M.A.N. } & $x$ & $\sqrt{ }$ & $x$ & $x$ & $x$ & $\sqrt{ }$ & $\sqrt{ }$ & $x$ & $\sqrt{ }$ & $x$ \\
\hline & & & & Reactive & & & & & & \\
\hline DSR & $\sqrt{ }$ & $x$ & $x$ & $\sqrt{ }$ & $\sqrt{ }$ & $x$ & $x$ & $\sqrt{ }$ & $\sqrt{ }$ & $x$ \\
\hline RE-DSR & $\sqrt{ }$ & $x$ & $x$ & $\sqrt{ }$ & $x$ & $x$ & $x$ & $\sqrt{ }$ & $\sqrt{ }$ & $x$ \\
\hline UE-DSR & $\sqrt{ }$ & $x$ & $x$ & $\sqrt{ }$ & $x$ & $x$ & $x$ & $\sqrt{ }$ & $\sqrt{ }$ & $x$ \\
\hline AODV & $\sqrt{ }$ & $x$ & $x$ & $\begin{array}{l}\sqrt{ } \\
\text { Hybrid }\end{array}$ & $x$ & $x$ & $x$ & $\sqrt{ }$ & $\sqrt{ }$ & $x$ \\
\hline ZRP & $x$ & $\sqrt{ }$ & $\sqrt{ }$ & $x$ & $x$ & $x$ & $x$ & $x$ & $x$ & $x$ \\
\hline \multirow[t]{2}{*}{ TORA } & $x$ & $\sqrt{ }$ & $\sqrt{ }$ & $x$ & $x$ & $x$ & $x$ & $x$ & $x$ & $x$ \\
\hline & \multicolumn{10}{|c|}{ Geographic/Position-based } \\
\hline GPSR & $\sqrt{ }$ & $\sqrt{ }$ & $x$ & $x$ & $x$ & $x$ & $\sqrt{ }$ & $x$ & $x$ & $\sqrt{ }$ \\
\hline GLSR & $\sqrt{ }$ & $\sqrt{ }$ & $x$ & $x$ & $x$ & $x$ & $\sqrt{ }$ & $x$ & $x$ & $\sqrt{ }$ \\
\hline MPGR & $\sqrt{ }$ & $\sqrt{ }$ & $x$ & $x$ & $x$ & $x$ & $\sqrt{ }$ & $x$ & $x$ & $\sqrt{ }$ \\
\hline GPMOR & $\sqrt{ }$ & $\sqrt{ }$ & $x$ & $x$ & $x$ & $x$ & $\sqrt{ }$ & $x$ & $x$ & $\sqrt{ }$ \\
\hline RGR & $\sqrt{ }$ & $\sqrt{ }$ & $x$ & $x$ & $x$ & $x$ & $\sqrt{ }$ & $x$ & $x$ & $\sqrt{ }$ \\
\hline DREAM & $x$ & $\sqrt{ }$ & $x$ & $x$ & $\sqrt{ }$ & $\sqrt{ }$ & $\sqrt{ }$ & $x$ & $\sqrt{ }$ & $x$ \\
\hline P-OLSR & $\sqrt{ }$ & $\sqrt{ }$ & $x$ & $\begin{array}{l}\sqrt{ } \\
\text { SI-based }\end{array}$ & $x$ & $x$ & $\sqrt{ }$ & $x$ & $\sqrt{ }$ & $x$ \\
\hline IAFSA & $\sqrt{ }$ & $\sqrt{ }$ & $x$ & $x$ & $x$ & $x$ & $\sqrt{ }$ & $x$ & $x$ & $\sqrt{ }$ \\
\hline BeeAdhoc & $\sqrt{ }$ & $\sqrt{ }$ & $x$ & $x$ & $x$ & $x$ & $\sqrt{ }$ & $x$ & $x$ & $\sqrt{ }$ \\
\hline APAR & $\sqrt{ }$ & $\sqrt{ }$ & $x$ & $x$ & $x$ & $x$ & $\sqrt{ }$ & $x$ & $x$ & $\sqrt{ }$ \\
\hline
\end{tabular}

Note: " $\sqrt{ }$ " = supported, “ $\times$ " = not supported. 


\section{Conclusions and Discussions}

With the development of UAV technology and network communication, the application mode of UAVs is also constantly developing. The UAV swarm is an SI-based solution proposed for the expansion of UAV application functions and multi-UAV cooperative operations. UAV swarms have been used in many scenarios, such as in disaster management, forest fire monitoring, and border monitoring. Therefore, it is of great practical significance to further pursue research on UAV swarm technology. UAV swarms are highly mobile and their topology frequently changes, which requires communication networks with low latency and high reliability. Therefore, it is necessary to design communication architectures and routing protocols with good applicability, high efficiency and stability for consistent UAV swarm communication.

In this article, we first introduced four communication architectures that can be deployed in UAV swarms, and also introduced three common intra-swarm communication architectures. Through the final summary table, we can conclude that the multi-layer architecture combined with the meshed intra-swarm architecture is currently the most applicable communication architecture. Subsequently, we presented a comprehensive classification of existing routing protocols for UAV communications, namely topology-based, geographic/position-based, and SI-based. These routing protocols were investigated, and their characteristics were described in detail. We also presented a summary table for comparative analysis. It is proved that topology-based routing cannot cope with UAV networks. SI-based routing and geographic/position-based routing are more suitable for UAV networks.

Although the existing theoretical research and experiments have solved some technical problems in UAV swarm communication architectures and routing protocols, there are still many interesting, important and yet challenging open issues deserving further investigation. Some of them are briefly summarized as follows:

(1) Multi-layer architecture can better adapt to the characteristics of the UAV swarm communication, but it also brings new challenges. Because of the importance of gateway UAVs in swarm communication, it is necessary to have the ability to detect the failure of gateway UAVs. Further, if malfunctions have occurred, there should be a reliable algorithm to select the next UAV to act as the gateway. At the same time, the data stored in fault gateway UAV should be able to synchronize to the standby one.

(2) The fast-moving characteristic of UAVs and the frequent change of network topology may cause the swarm communication to be intermittently connected. It has always been one of the important issues with routing protocols. Therefore, the solution to the problem of intermittent connectivity will remain the focus of research in the future.

(3) Currently, most proposed routing protocols focus on performance improvement. However, security is an important content that cannot be ignored in any communication network. Therefore, it is necessary to propose new routing solutions including security components.

(4) Energy efficiency plays an important role in UAV networks with energy constraints. The concerns regarding power saving in the UAV networks are in some ways similar to that in mobile ad hoc networks and wireless sensor networks. Many energy-saving routing protocols have been tried for UAV networks, but the applicability of these protocols in different drone network scenarios has yet to be proven.

(5) In addition, the UAV communication network should be compatible with other networks in specific mission scenarios. Therefore, the design of the new routing protocols should be able to effectively support the different transmission requirements in the diverse mission scenarios.

Author Contributions: Conceptualization, X.C., J.T. and S.L.; methodology, X.C.; validation, X.C., J.T. and S.L.; formal analysis, J.T.; investigation, X.C.; resources, S.L.; data curation, J.T.; writing-original draft preparation, X.C.; writing-review and editing, X.C. and J.T.; visualization, X.C.; supervision, S.L.; project administration, S.L.; funding acquisition, J.T. All authors have read and agreed to the published version of the manuscript. 
Funding: This research was funded by the Natural Science Foundation of Hunan Province, China, grant number 2019JJ20021, NUDT Scientific Research Project, China, grant number ZK18-02-12, Hu-nan Science and Technology Innovation Plan Project, China, grant number 2018RS3079, Young Talents Lifting Project, China, grant number 17XXXT048 and Complex Situational Cognitive Technology, China, grant number XXX050202.

Conflicts of Interest: The authors declare no conflict of interest. The funders had no role in the design of the study; in the collection, analyses, or interpretation of data; in the writing of the manuscript, or in the decision to publish the results.

\section{Abbreviations}

\begin{tabular}{|c|c|}
\hline AODV & Ad hoc On Demand Distance Vector \\
\hline APAR & Ant colony optimization-based Polymorphism-Aware Routing \\
\hline B.A.T.M.A.N. & Better Approach to Mobile Ad hoc Networking \\
\hline BeeAdhoc & Bee colony algorithm based Ad hoc network \\
\hline CAS & Close Air Support \\
\hline DCR & Data Centric Routing \\
\hline DOLSR & Directional Optimized Link State Routing \\
\hline DREAM & Distance Routing Effect Algorithm for Mobility \\
\hline DSDV & Destination-Sequenced Distance Vector \\
\hline DSR & Dynamic Source Routing \\
\hline GGF & Greedy Geographic Forwarding \\
\hline GLS & Grid Location Services \\
\hline GLSR & Geographic Load Share Routing \\
\hline GPMOR & Geographic Position Mobility Oriented Routing \\
\hline GPSR & Greedy Perimeter Stateless Routing \\
\hline G-T-G & Group-to-Group \\
\hline HLS & Hierarchical Location Services \\
\hline HRP & Hybrid Routing Protocol \\
\hline IAFSA & Improved Artificial Fish-swarm Algorithm \\
\hline IP & Internet Protocol \\
\hline LCAD & Load Carry and Deliver Routing \\
\hline MLHR & Multilevel Hierarchical Routing \\
\hline ML-OLSR & Mobility and Load-aware Optimized Link State Routing \\
\hline MPGR & Mobility Prediction based Geographic Routing \\
\hline MPR & Multiple Point Relay \\
\hline OLSR & Optimized Link State Routing \\
\hline PRP & Proactive Routing Protocol \\
\hline QoS & Quality of Service \\
\hline RE-DSR & Restrict Dynamic Source Routing \\
\hline RGR & Reactive-Greedy-Reactive \\
\hline RLS & Reactive Location Services \\
\hline RREP & Route Reply \\
\hline RREQ & Route Requests \\
\hline RRP & Reactive Routing Protocol \\
\hline SI & Swarm Intelligence \\
\hline SPOF & Single Point of Failure \\
\hline $\mathrm{TC}$ & Topology Control \\
\hline TORA & Temporarily Ordered Routing Algorithm \\
\hline UAV & Unmanned Aerial Vehicle \\
\hline UE-DSR & UAV Energy Dynamic Source Routing \\
\hline U-T-I & UAV-to-Infrastructure \\
\hline U-T-U & UAV-to-UAV \\
\hline ZRP & Zone Routing Protocol \\
\hline
\end{tabular}




\section{References}

1. Manathara, J.G.; Sujit, P.B.; Sousa, J. Search Strategies for Multiple UAV Search and Destroy Missions. J. Intell. Robot. Syst. 2010, 61, 355-367. [CrossRef]

2. Sun, Z.; Wang, P.; Vuran, M.C.; Al-Rodhaan, M.; Al-Dhelaan, A.; Akyildiz, I.F. BorderSense: Border patrol through advanced wireless sensor networks. Ad Hoc Netw. 2011, 9, 468-477. [CrossRef]

3. Rosati, S.; Krużelecki, K.; Traynard, L.; Mobile, B.R. Speed-aware routing for UAV ad-hoc networks. In Proceedings of the 2013 IEEE Globecom Workshops (GC Wkshps), Atanta, GA, USA, 9-13 December 2013; IEEE: New York, NY, USA, 2013; pp. 1367-1373.

4. Erdelj, M.; Chowdhury, K.R.; Akyildiz, I.F.; Natalizio, E. Help from the Sky: Leveraging UAVs for Disaster Management. IEEE Pervasive Comput. 2017, 16, 24-32. [CrossRef]

5. Beard, R.W.; McLain, T.W.; Nelson, D.B.; Kingston, D.; Johanson, D. Decentralized cooperative aerial surveillance using fixed-wing miniature UAVs. Proc. IEEE 2006, 94, 1306-1324. [CrossRef]

6. Barrado, C.; Meseguer-Pallarés, R.; Lopez, J.; Pastor, E.; Santamaria, E.; Royo, P. Wildfire monitoring using a mixed air-ground mobile network. IEEE Pervasive Comput. 2010, 9, 24-32. [CrossRef]

7. Cho, A.; Kim, J.; Lee, S.; Kee, C. Wind Estimation and Airspeed Calibration using a UAV with a Single-Antenna GPS Receiver and Pitot Tube. IEEE Trans. Aerosp. Electron. Syst. 2011, 47, 109-117. [CrossRef]

8. Maza, I.; Caballero, F.; Capitán, J.; De-Dios, J.R.M.; Ollero, A. Experimental Results in Multi-UAV Coordination for Disaster Management and Civil Security Applications. J. Intell. Robot. Syst. 2010, 61, 563-585. [CrossRef]

9. Xiang, H.; Tian, L. Development of a low-cost agricultural remote sensing system based on an autonomous unmanned aerial vehicle (UAV). Biosyst. Eng. 2011, 108, 174-190. [CrossRef]

10. Semsch, E.; Jakob, M.; Pavlicek, D.; Pechoucek, M. Autonomous UAV surveillance in complex urban environments. In Proceedings of the 2009 IEEE/WIC/ACM International Joint Conference on Web Intelligence and Intelligent Agent Technology, Milan, Italy, 15-18 September 2009; IEEE: New York, NY, USA, 2009; Volume 2, pp. 82-85.

11. De Freitas, E.P.; Heimfarth, T.; Netto, I.F.; Lino, C.E.; Pereira, C.E.; Ferreira, A.M.; Wagner, F.R.; Larsson, T. UAV relay network to support WSN connectivity. In Proceedings of the International Congress on Ultra Modern Telecommunications and Control Systems, Dublin, Ireland, 28-30 October 2010; IEEE: New York, NY, USA, 2010; pp. 309-314.

12. Jiang, F.; Swindlehurst, A.L. Dynamic UAV relay positioning for the ground-to-air uplink. In Proceedings of the 2010 IEEE Globecom Workshops, Miami, FL, USA, 6 December 2010; IEEE: New York, NY, USA, 2010; pp. 1766-1770.

13. Adams, S.M.; Friedland, C.J. A Survey of Unmanned Aerial Vehicle (UAV) Usage for Imagery Collection in Disaster Research and Management. In Proceedings of the 9th International Workshop on Remote Sensing for Disaster Response; 2011; Volume 8. Available online: https://www.researchgate.net/publication/266465037_A_Survey_ of_Unmanned_Aerial_Vehicle_UAV_Usage_for_Imagery_Collection_in_Disaster_Research_and_Management (accessed on 31 January 2011).

14. Liu, X.; Yin, D.; Zhou, Y.; Liu, Z.; Wang, Y. Dispatching and management methods for communication of UAV swarm. In Proceedings of the 2nd International Conference on High Performance Compilation, Computing and Communications, New York, NY, USA, 15-17 March 2018; pp. 61-67.

15. Morse, B.S.; Engh, C.H.; Goodrich, M.A. UAV video coverage quality maps and prioritized indexing for wilderness search and rescue. In Proceedings of the 2010 5th ACM/IEEE International Conference on Human-Robot Interaction (HRI), Osaka, Japan, 2-5 March 2010; IEEE: New York, NY, USA, 2010; pp. 227-234.

16. Yanmaz, E.; Costanzo, C.; Bettstetter, C.; Elmenreich, W. A discrete stochastic process for coverage analysis of autonomous UAV networks. In Proceedings of the 2010 IEEE Globecom Workshops, Miami, FL, USA, 6 December 2010; IEEE: New York, NY, USA, 2010; pp. 1777-1782.

17. Sahingoz, O.K. Networking Models in Flying Ad-Hoc Networks (FANETs): Concepts and Challenges. J. Intell. Robot. Syst. 2013, 74, 513-527. [CrossRef]

18. Valavanis, K.P.; Vachtsevanos, G.J. Handbook of Unmanned Aerial Vehicles; Springer: Berlin/Heidelberg, Germany, 2015; Volume 1.

19. To, L.; Bati, A.; Hilliard, D. Radar cross section measurements of small unmanned air vehicle systems in non-cooperative field environments. In Proceedings of the 2009 3rd European Conference on Antennas and Propagation, Berlin, Germany, 23-27 March 2009; IEEE: New York, NY, USA, 2009; pp. 3637-3641. 
20. Tahir, A.; Böling, J.; Haghbayan, M.-H.; Toivonen, H.T.; Plosila, J. Swarms of Unmanned Aerial Vehicles-A Survey. J. Ind. Inf. Integr. 2019, 16, 100106. [CrossRef]

21. Parunak, H.V.D.; Brueckner, S.; Odell, J. Swarming coordination of multiple UAV's for collaborative sensing. In Proceedings of the 2nd AIAA “Unmanned Unlimited" Conference and Workshop \& Exhibit, San Diego, CA, USA, 15-18 September 2003; p. 6525.

22. Varela, G.; Caamaño, P.; Orjales, F.; Deibe, A.; Lopez-Pena, F.; Duro, R.J. Swarm intelligence based approach for real time UAV team coordination in search operations. In Proceedings of the 2011 Third World Congress on Nature and Biologically Inspired Computing, Salamanca, Spain, 19-21 October 2011; IEEE: New York, NY, USA, 2011; pp. 365-370.

23. Weaver, J.N.; Arroyo, A.A.; Schwartz, E.M. Collaborative coordination and control for an implemented heterogeneous swarm of uavs and ugvs. Unpubl. Dr. Diss. 2014. Available online: https://www.mil.ufl.edu/ publications/PhD_Dissertation_Joshua_Weaver.pdf (accessed on 8 May 2014).

24. Zhu, X.; Liu, Z.; Yang, J. Model of Collaborative UAV Swarm Toward Coordination and Control Mechanisms Study. Procedia Comput. Sci. 2015, 51, 493-502. [CrossRef]

25. McCune, R.; Purta, R.; Dobski, M.; Jaworski, A.; Madey, G.; Madey, A.; Wei, Y.; Blake, M.B. Investigations of dddas for command and control of uav swarms with agent-based modeling. In Proceedings of the 2013 Winter Simulations Conference (WSC), Washongtong, DC, USA, 8 December 2013; IEEE: New York, NY, USA, 2013; pp. 1467-1478.

26. He, L.; Bai, P.; Liang, X.; Zhang, J.; Wang, W. Feedback formation control of UAV swarm with multiple implicit leaders. Aerosp. Sci. Technol. 2018, 72, 327-334. [CrossRef]

27. Akram, R.N.; Markantonakis, K.; Mayes, K.; Habachi, O.; Sauveron, D.; Steyven, A.; Chaumette, S. Security, privacy and safety evaluation of dynamic and static fleets of drones. In Proceedings of the 2017 IEEE/AIAA 36th Digital Avionics Systems Conference (DASC), St. Petersburg, FL, USA, 17-21 September 2017; IEEE: New York, NY, USA, 2017; pp. 1-12.

28. Bürkle, A.; Segor, F.; Kollmann, M. Towards Autonomous Micro UAV Swarms. J. Intell. Robot. Syst. 2010, 61, 339-353. [CrossRef]

29. Sharma, R.; Ghose, D. Collision avoidance between UAV clusters using swarm intelligence techniques. Int. J. Syst. Sci. 2009, 40, 521-538. [CrossRef]

30. Lamont, G.B.; Slear, J.N.; Melendez, K. UAV swarm mission planning and routing using multi-objective evolutionary algorithms. In Proceedings of the 2007 IEEE Symposium on Computational Intelligence in Multi-Criteria Decision-Making, Honolulu, HI, USA, 1-5 April 2007; IEEE: New York, NY, USA, 2007; pp. 10-20.

31. Sampedro, C.; Bavle, H.; Sanchez-Lopez, J.L.; Fernández, R.A.S.; Rodríguez-Ramos, A.; Molina, M.; Campoy, P. A flexible and dynamic mission planning architecture for uav swarm coordination. In Proceedings of the 2016 International Conference on Unmanned Aircraft Systems (ICUAS), Arlington, VA, USA, 15 September 2016; IEEE: New York, NY, USA, 2016; pp. 355-363.

32. Wei, Y.; Madey, G.R.; Blake, M.B. Agent-based simulation for UAV swarm mission planning and execution. In Proceedings of the Agent-Directed Simulation Symposium, San Diego, CA, USA, 7 April 2013; pp. 1-8.

33. Zettl, K.; Muhammad, S.S.; Chlestil, C.; Leitgeb, E.; Friedl, A.; Schmitt, N.; Rehm, W. High bit rate optical wireless systems for swarm unmanned aerial vehicles: A feasibility study. Mediterr. J. Comput. Netw. 2007, 3, 142-150.

34. Jawhar, I.; Mohamed, N.; Al-Jaroodi, J.; Agrawal, D.P.; Zhang, S. Communication and networking of UAV-based systems: Classification and associated architectures. J. Netw. Comput. Appl. 2017, 84, 93-108. [CrossRef]

35. Khan, M.A.; Safi, A.; Qureshi, I.M.; Khan, I.U. Flying ad-hoc networks (FANETs): A review of communication architectures, and routing protocols. In Proceedings of the 2017 First International Conference on Latest trends in Electrical Engineering and Computing Technologies (IN ${ }^{\mathrm{TEL}} \mathrm{LECT}$ ), Saidia, Morocco, 15-17 April 2017; IEEE: New York, NY, USA, 2017; pp. 1-9.

36. Cao, Y.; Yu, W.; Ren, W.; Chen, G. An Overview of Recent Progress in the Study of Distributed Multi-Agent Coordination. IEEE Trans. Ind. Inform. 2012, 9, 427-438. [CrossRef]

37. Chriki, A.; Touati, H.; Snoussi, H.; Kamoun, F. UAV-GCS Centralized Data-Oriented Communication Architecture for Crowd Surveillance Applications. In Proceedings of the 2019 15th International Wireless Communications \& Mobile Computing Conference (IWCMC), Tangier, Morocco, 24-28 June 2018; IEEE: New York, NY, USA, 2019; pp. 2064-2069. 
38. Gupta, L.; Jain, R.; Vaszkun, G. Survey of Important Issues in UAV Communication Networks. IEEE Commun. Surv. Tutor. 2015, 18, 1123-1152. [CrossRef]

39. Sahingoz, O.K. Mobile networking with UAVs: Opportunities and challenges. In Proceedings of the 2013 International Conference on Unmanned Aircraft Systems (ICUAS), Atlanta, GA, USA, 28-31 May 2013; IEEE: New York, NY, USA, 2013; pp. 933-941.

40. Kaleem, Z.; Yousaf, M.; Qamar, A.; Ahmad, A.; Duong, T.Q.; Choi, W.; Jamalipour, A. UAV-Empowered Disaster-Resilient Edge Architecture for Delay-Sensitive Communication. IEEE Netw. 2019, 33, 124-132. [CrossRef]

41. Sun, Y.; Mi, Z.; Wang, H.; Jiang, Y.; Zhao, N. Research on UAV Cluster Routing Strategy Based on Distributed SDN. In Proceedings of the 2019 IEEE 19th International Conference on Communication Technology (ICCT), Xi'an, China, 16-19 October 2019; IEEE: New York, NY, USA, 2019; pp. 1269-1274.

42. Zhao, Z.; Braun, T. Topology control and mobility strategy for uav ad-hoc networks: A survey. In Proceedings of the Joint ERCIM eMobility and MobiSense Workshop, St Petersburg, Russia, 1 June 2012; pp. 27-32.

43. De Souza, B.J.O.; Endler, M. Coordinating movement within swarms of UAVs through mobile networks. In Proceedings of the 2015 IEEE International Conference on Pervasive Computing and Communication Workshops (PerCom Workshops), St. Louis, MO, USA, 23-27 March 2015; IEEE: New York, NY, USA, 2015; pp. 154-159.

44. Zafar, W.; Khan, B.M. Flying Ad-Hoc Networks: Technological and Social Implications. IEEE Technol. Soc. Mag. 2016, 35, 67-74. [CrossRef]

45. Zhang, K.; Zhang, W.; Zeng, J.-Z. Preliminary study of routing and date integrity in mobile Ad hoc UAV network. In Proceedings of the 2008 International Conference on Apperceiving Computing and Intelligence Analysis, Chengdu, China, 13-15 December 2008; IEEE: New York, NY, USA, 2008; pp. 347-350.

46. Fu, B.; DaSilva, L.A. A mesh in the sky: A routing protocol for airborne networks. In Proceedings of the MILCOM 2007-IEEE Military Communications Conference, Orlando, FL, USA, 29-31 October 2007; IEEE: New York, NY, USA, 2007; pp. 1-7.

47. Shen, J.; Moh, S.; Chung, I. Routing protocols in delay tolerant networks: A comparative survey. In Proceedings of the 23rd International Technical Conference on Circuits/Systems, Computers and Communications (ITC-CSCC 2008), California, CA, USA, 26-31 October 2008; pp. 6-9.

48. Le, M.; Park, J.-S.; Gerla, M. UAV assisted disruption tolerant routing. In Proceedings of the MILCOM 2006-2006 IEEE Military Communications Conference, Washington, DC, USA, 23-25 October 2006; IEEE: New York, NY, USA, 2006; pp. 1-5.

49. Cheng, C.-M.; Hsiao, P.-H.; Kung, H.; Vlah, D. Maximizing throughput of UAV-relaying networks with the load-carry-and-deliver paradigm. In Proceedings of the 2007 IEEE Wireless Communications and Networking Conference, Hong Kong, China, 13-15 March 2007; IEEE: New York, NY, USA, 2007; pp. 4417-4424.

50. De Jong, E. Flexible Data-Centric UAV Platform Eases Mission Adaptation. White Paper. Available online: http://wk.ixueshu.com/i-wlwx/8f45d985a8149351.html (accessed on 20 March 2009).

51. Koller, A.; Johnson, E. Design, implementation, and integration of a publish/subscribe-like multi-UAV communication architecture. In Proceedings of the AIAA Modeling and Simulation Technologies Conference and Exhibit, Monterey, CA, USA, 5-8 August 2005; p. 6309.

52. Bekmezci, I.; Sahingoz, O.K. Temel, Şamil Flying Ad-Hoc Networks (FANETs): A survey. Ad Hoc Netw. 2013, 11, 1254-1270. [CrossRef]

53. Ko, J.; Mahajan, A.; Sengupta, R. A network-centric UAV organization for search and pursuit operations. In Proceedings of the IEEE Aerospace Conference, Big Sky, MT, USA, 9-16 March 2002; IEEE: New York, NY, USA, 2002; Volume 6, p. 6.

54. López, J.; Royo, P.; Pastor, E.; Barrado, C.; Santamaria, E. A middleware architecture for unmanned aircraft avionics. In Proceedings of the 2007 ACM/IFIP/USENIX International Conference on Middleware Companion, Newport Beach, CA, USA, 1 November 2007; pp. 1-6.

55. Liu, K.; Zhang, J.; Zhang, T. The clustering algorithm of UAV networking in near-space. In Proceedings of the 2008 8th International Symposium on Antennas, Propagation and EM Theory, Kun Ming, China, 2-5 November 2008; IEEE: New York, NY, USA, 2008; pp. 1550-1553.

56. Jacquet, P.; Muhlethaler, P.; Clausen, T.; Laouiti, A.; Qayyum, A.; Viennot, L. Optimized link state routing protocol for ad hoc networks. In Proceedings of the IEEE International Multi Topic Conference, 2001. IEEE INMIC 2001. Technology for the 21st Century, Lahore, Pakistam, 30 December 2001; IEEE: New York, NY, USA, 2001; pp. 62-68. 
57. Singh, K.; Verma, A.K. Applying OLSR routing in FANETs. In Proceedings of the 2014 IEEE International Conference on Advanced Communications, Control and Computing Technologies, Bangalore, India, 6-7 January 2014; IEEE: New York, NY, USA, 2014; pp. 1212-1215.

58. Singh, K.; Verma, A.K. Experimental analysis of AODV, DSDV and OLSR routing protocol for flying adhoc networks (FANETs). In Proceedings of the 2015 IEEE International Conference on Electrical, Computer and Communication Technologies (ICECCT), Tamilnadu, India, 5-7 March 2015; IEEE: New York, NY, USA, 2015; pp. 1-4.

59. Vasiliev, D.S.; Meitis, D.S.; Abilov, A. Simulation-based comparison of AODV, OLSR and HWMP protocols for flying Ad Hoc networks. In Proceedings of the International Conference on Next Generation Wired/Wireless Networking, St. Petersburg, Russia, 27-28 August 2014; Springer: Berlin/Heidelberg, Germany, 2014; pp. 245-252.

60. Alshbatat, A.I.; Dong, L. Cross layer design for mobile ad-hoc unmanned aerial vehicle communication networks. In Proceedings of the 2010 International Conference on Networking, Sensing and Control (ICNSC), Chicago, IL, USA, 10-12 April 2010; IEEE: New York, NY, USA, 2010; pp. 331-336.

61. Alshabtat, A.I.; Dong, L.; Li, J.; Yang, F. Low latency routing algorithm for unmanned aerial vehicles ad-hoc networks. Int. J. Electr. Comput. Eng. 2010, 6, 48-54.

62. Zheng, Y.; Wang, Y.; Li, Z.; Dong, L.; Jiang, Y.; Zhang, H. A Mobility and Load Aware OLSR Routing Protocol for UAV Mobile ad-hoc Networks. 2014. Available online: https://ieeexplore.ieee.org/document/6913628 (accessed on 2 October 2014).

63. Bani, M.; Yassein, M.B.; Damer, A. Flying Ad-Hoc Networks: Routing Protocols, Mobility Models, Issues. Int. J. Adv. Comput. Sci. Appl. 2016, 7, 162-168. [CrossRef]

64. Perkins, C.E.; Bhagwat, P. Highly dynamic Destination-Sequenced Distance-Vector routing (DSDV) for mobile computers. ACM SIGCOMM Comput. Commun. Rev. 1994, 24, 234-244. [CrossRef]

65. Turnadereli, I.; Bekmezci, I. Performance comparison of MANET routing protocols for UAV ad hoc networks. In Proceedings of the International Symposium on Computing in Science \& Engineering, Nakorn Pathom, Thailand, 4-6 September 2015; p. 169.

66. Neumann, A.; Aichele, C.; Lindner, M.; Wunderlich, S. Better approach to mobile ad-hoc networking (BATMAN). IETF Draft 2008, 1-24. Available online: http://www.researchgate.net/publication/320172464_ Better_approach_to_mobile_ad-hoc_networking_BATMAN (accessed on 1 October 2008).

67. Sandhu, D.S.; Sharma, S. Performance evaluation of batman, DSR, OLSR routing protocols-A review. J. Inf. Oper. Manag. 2012, 3, 225.

68. Murray, D.; Dixon, M.; Koziniec, T. An experimental comparison of routing protocols in multi hop ad hoc networks. In Proceedings of the 2010 Australasian Telecommunication Networks and Applications Conference, Auckland, New Zealand, 31 October-3 November 2010; IEEE: New York, NY, USA, 2010; pp. 159-164.

69. Sharma, A.; Rajagopalan, N. A comparative study of BATMAN and OLSR routing protocols for MANETs. Int. J. Adv. Trends Comput. Sci. Eng. 2013, 2, 13-17.

70. Habib, S.; Saleem, S.; Saqib, K.M. Review on MANET routing protocols and challenges. In Proceedings of the 2013 IEEE Student Conference on Research and Development, Putrajaya, Malaysia, 16-17 December 2013; IEEE: New York, NY, USA, 2013; pp. 529-533.

71. Brown, T.X.; Doshi, S.; Jadhav, S.; Henkel, D.; Thekkekunnel, R.-G. A full scale wireless ad hoc network test bed. Proc. ISART'05 2005, 51-60. Available online: http://citeseerx.ist.psu.edu/viewdoc/summary?doi=10.1.1. 121.2433 (accessed on 22 October 2018).

72. Khare, V.R.; Wang, F.Z.; Wu, S.; Deng, Y.; Thompson, C. Ad-hoc network of unmanned aerial vehicle swarms for search \& destroy tasks. In Proceedings of the 2008 4th International IEEE Conference Intelligent Systems, Varna, Bulgaria, 6-8 September 2008; IEEE: New York, NY, USA, 2008; Volume 1, pp. 6-65.

73. Li, J.; Zhang, X.L.; Bao, J.H.; Geng, G.L. A Novel DSR-Based Protocol for Signal Intensive UAV Network. Appl. Mech. Mater. 2012, 241, 2284-2289. [CrossRef]

74. Li, J.; Liu, X.C.; Pang, Y.F.; Zhu, W.W. A Novel DSR-Based Protocol for Small Reconnaissance UAV Ad Hoc Network. Appl. Mech. Mater. 2014, 568, 1272-1277. [CrossRef]

75. Perkins, C.; Belding-Royer, E.; Das, S. RFC3561: Ad Hoc on-Demand Distance Vector (AODV) Routing; RFC: 2003. Available online: https://dl.acm.org/doi/pdf/10.17487/RFC3561 (accessed on 1 July 2003). 
76. Biomo, J.-D.M.M.; Kunz, T.; St-Hilaire, M. Routing in unmanned aerial ad hoc networks: Introducing a route reliability criterion. In Proceedings of the 2014 7th IFIP Wireless and Mobile Networking Conference (WMNC), Vilamoura, Portugal, 20-22 May 2014; IEEE: New York, NY, USA, 2014; pp. 1-7.

77. Perkins, C. ZRP: A hybrid framework for routing in ad hoc networks. In Ad Hoc Networks; Addison-Wesley: Boston, MA, USA, 2001; pp. 221-254.

78. Haas, Z. The zone routing protocol (ZRP) for ad hoc networks. IETF Internet Draft Draft-Ietf-Manet-Zone-Zrp-01 Txt 1998. Available online: https://tools.ietf.org/html/draft-ietf-manet-zone-zrp-01 (accessed on 1 August 1998).

79. Zang, C.; Zang, S. Mobility prediction clustering algorithm for UAV networking. In Proceedings of the 2011 IEEE GLOBECOM Workshops (GC Wkshps), Houston, TX, USA, 5-9 December 2011; IEEE: New York, NY, USA, 2011; pp. 1158-1161.

80. Park, V.D.; Corson, M.S. A performance comparison of the temporally-ordered routing algorithm and ideal link-state routing. In Proceedings of the Third IEEE Symposium on Computers and Communications. ISCC'98 (Cat. No. 98EX166), Athens, Greece, 30 June-2 July 1998; IEEE: New York, NY, USA, 1998; pp. 592-598.

81. Käsemann, M.; Füßler, H.; Hartenstein, H.; Mauve, M. A reactive location service for mobile ad hoc networks. Tech. Rep. 2002, 2, 1-16.

82. Li, J.; Jannotti, J.; De Couto, D.S.J.; Karger, D.R.; Morris, R. A scalable location service for geographic ad hoc routing. In Proceedings of the 6th Annual International Conference; Association for Computing Machinery (ACM), Boston, MA, USA, 6-11 August 2000; pp. 120-130.

83. Karp, B.; Kung, H.T. GPSR: Greedy Perimeter Stateless Routing for Wireless Networks. In Proceedings of the GPSR: Greedy Perimeter Stateless Routing for Wireless Networks; Defense Technical Information Center (DTIC), Niagara Falls, Ont., Canada, 21-23 May 2007; pp. 243-254.

84. Hyland, M.; Mullins, B.E.; Baldwin, R.O.; Temple, M.A. Simulation-based performance evaluation of mobile ad hoc routing protocols in a swarm of unmanned aerial vehicles. In Proceedings of the 21st International Conference on Advanced Information Networking and Applications Workshops (AINAW'07), Niagara Falls, Ont., Canada, 21-23 May 2007; IEEE: New York, NY, USA, 2007; Volume 2, pp. 249-256.

85. Shirani, R.; St-Hilaire, M.; Kunz, T.; Zhou, Y.; Li, J.; Lamont, L. The performance of greedy geographic forwarding in unmanned aeronautical ad-hoc networks. In Proceedings of the 2011 Ninth Annual Communication Networks and Services Research Conference, Ottawa, ON, Canada, 2-5 May 2011; IEEE: New York, NY, USA, 2011; pp. 161-166.

86. Medina, D.; Hoffmann, F.; Rossetto, F.; Rokitansky, C.-H. A Geographic Routing Strategy for North Atlantic In-Flight Internet Access Via Airborne Mesh Networking. IEEE/ACM Trans. Netw. 2011, 20, 1231-1244. [CrossRef]

87. Medina, D.; Hoffmann, F.; Rossetto, F.; Rokitansky, C.-H. North atlantic inflight internet connectivity via airborne mesh networking. In Proceedings of the 2011 IEEE Vehicular Technology Conference (VTC Fall), San Francisco, CA, USA, 5-8 September 2011; IEEE: New York, NY, USA, 2011; pp. 1-5.

88. Medina, D.; Hoffmann, F.; Rossetto, F.; Rokitansky, C.-H. A crosslayer geographic routing algorithm for the airborne internet. In Proceedings of the 2010 IEEE International Conference on Communications, Cape Town, South Africa, 23-27 May 2010; IEEE: New York, NY, USA, 2010; pp. 1-6.

89. Medina, D.; Hoffmann, F.; Rossetto, F.; Rokitansky, C.-H. Routing in the airborne internet. In Proceedings of the 2010 Integrated Communications, Navigation, and Surveillance Conference, Hemdon, VA, USA, 11-13 May 2010; IEEE: New York, NY, USA, 2010; pp. A7-1-A7-10.

90. Lin, L.; Sun, Q.; Wang, S.; Yang, F. A geographic mobility prediction routing protocol for ad hoc UAV network. In Proceedings of the 2012 IEEE Globecom Workshops, Anaheim, CA, USA, 3-7 December 2012; IEEE: New York, NY, USA, 2012; pp. 1597-1602.

91. Lin, L.; Sun, Q.; Li, J.; Yang, F. A novel geographic position mobility oriented routing strategy for UAVs. J. Comput. Inf. Syst. 2012, 8, 709-716.

92. Shirani, R.; St-Hilaire, M.; Kunz, T.; Zhou, Y.; Li, J.; Lamont, L. Combined reactive-geographic routing for unmanned aeronautical ad-hoc networks. In Proceedings of the 2012 8th International Wireless Communications and Mobile Computing Conference (IWCMC), Limassol, Cyprus, 27-31 August 2012; IEEE: New York, NY, USA, 2012; pp. 820-826. 
93. Taniuchi, K.; Ohba, Y.; Fajardo, V.; Das, S.; Tauil, M.; Cheng, Y.-H.; Dutta, A.; Baker, D.; Yajnik, M.; Famolari, D. IEEE 802.21: Media independent handover: Features, applicability, and realization. IEEE Commun. Mag. 2009, 47, 112-120. [CrossRef]

94. Camp, T.; Boleng, J.; Williams, B.; Wilcox, L.; Navidi, W. Performance comparison of two location based routing protocols for ad hoc networks. In Proceedings of the Twenty-First Annual Joint Conference of the IEEE Computer and Communications Societies, New York, NY, USA, 23-27 June 2002; IEEE: New York, NY, USA, 2002; Volume 3, pp. 1678-1687.

95. Wu, J.; Wang, J.; Cao, Y.; Cao, Y.; Shi, X. Research of Multi-UAVs Communication Range Optimization Based on Improved Artificial Fish-Swarm Algorithm. In Proceedings of the Industrial Engineering, Machine Design and Automation (IEMDA 2014) \& Computer Science and Application (CCSA 2014) Proceedings of the 2014 Congress on IEMDA 2014 \& Proceedings of the 2nd Congress on CCSA 2014, Sanya, China, 12-14 December 2014; pp. 98-104.

96. Leonov, A.V. Application of bee colony algorithm for FANET routing. In Proceedings of the 2016 17th International Conference of Young Specialists on Micro/Nanotechnologies and Electron Devices (EDM), Erlagol, Russia, 30 June-4 July 2016; IEEE: New York, NY, USA, 2016; pp. 124-132.

97. Yu, Y.; Ru, L.; Chi, W.; Liu, Y.; Yu, Q.; Fang, K. Ant colony optimization based polymorphism-aware routing algorithm for ad hoc UAV network. Multimed. Tools Appl. 2016, 75, 14451-14476. [CrossRef]

(C) 2020 by the authors. Licensee MDPI, Basel, Switzerland. This article is an open access article distributed under the terms and conditions of the Creative Commons Attribution (CC BY) license (http://creativecommons.org/licenses/by/4.0/). 